\title{
Association between FBP1 and hypoxia-related gene expression in clear cell renal cell carcinoma
}

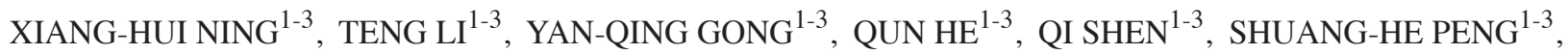 \\ JIANG-YI WANG ${ }^{1-3}$, JIN-CHAO CHEN ${ }^{1-3}$, YING-LU GUO ${ }^{1-3}$ and $\mathrm{KAN} \mathrm{GONG}^{1-3}$ \\ ${ }^{1}$ Department of Urology, Peking University First Hospital; ${ }^{2}$ Institute of Urology; \\ ${ }^{3}$ National Urological Cancer Center, Peking University, Beijing 100034, P.R. China
}

Received March 7, 2015; Accepted March 18, 2016

DOI: $10.3892 / 01.2016 .4504$

\begin{abstract}
Fructose-1,6-bisphosphatase 1 (FBP1) is a rate-limiting enzyme in gluconeogenesis. Recently, the catalytic activity-independent function of FBP1, hypoxia-induced factor (HIF) repression in the nucleus, was identified. The aim of the present study was to investigate the association between FBP1 and hypoxia-related gene expression in clear cell renal cell carcinoma (ccRCC). The protein expression levels of FBP1, HIF-1 $\alpha$, HIF-2 $\alpha$, erythropoietin (EPO) and carbonic anhydrase IX (CA9) were assessed by immunohistochemical staining of ccRCC paraffin blocks from 123 patients using the tissue microarray technique. The expression level of FBP1 was then correlated with various clinicopathological factors, and the protein expression levels of HIF-1 $\alpha$, HIF- $2 \alpha$, EPO and CA9. Clinicopathological factors, including age, gender, $\mathrm{T}$ stage and Fuhrman grade, were not significantly different between patients with low and high FBP1 expression in ccRCC $(\mathrm{P}>0.05)$. FBP1 protein expression level was significantly correlated with the expression levels of HIF-1 $\alpha(\mathrm{P}=0.005)$ and EPO $(\mathrm{P}=0.010)$, but not significantly correlated with the expression levels of HIF-2 $\alpha(\mathrm{P}=0.123)$ and $\mathrm{CA} 9(\mathrm{P}=0.513)$ in ccRCC tissues. The current findings confirm the association between FBP1 and hypoxia-related gene expression, and may facilitate understanding of the mechanisms of ccRCC tumorigenesis.
\end{abstract}

\section{Introduction}

Renal cell carcinoma (RCC) accounts for 3\% of all solid tumors, with $\sim 65,150$ men and women diagnosed in United

Correspondence to: Professor Kan Gong or Professor Ying-Lu Guo, Department of Urology, Peking University First Hospital, 8 Xishiku Street, Xicheng, Beijing 100034, P.R. China

E-mail: gongkan_pku@126.com

E-mail: gyl07@sina.com

Key words: fructose-1,6-bisphosphatase, clear cell renal cell carcinoma, hypoxia-related genes
States in 2013 (1). Clear cell RCC (ccRCC) is the most common subtype of RCC (2). Von Hippel-Lindau ( $V H L)$ gene mutation is a notable cause of ccRCC. The $V H L$ gene is located on chromosome 3 p25-26, and the gene product regulates the response to oxygen availability and functions as tumor suppressor through degradation of hypoxia-induced factor (HIF) $(3,4)$. HIF consists of unstable $\alpha$ and stable $\beta$ subunits. Three HIF- $\alpha$ genes, $H I F-1 \alpha, H I F-2 \alpha$ and $H I F-3 \alpha$, have been identified in humans. HIF- $1 \alpha$ and HIF- $2 \alpha$ are the most important in tumorigenesis; HIF- $2 \alpha$ modulates the expression of genes involved in energy metabolism, angiogenesis and apoptosis, while HIF-1 $\alpha$ is the major oxygen homeostasis regulator (5).

Concurrent hypoxia in the local microenvironment, and mutation or hypermethylation of the VHL gene, result in excessive HIF accumulation in cells. HIF is then transferred into nucleus, where it binds to hypoxia response elements in the promoters of hypoxia response genes, such as carbonic anhydrase IX (CA9) and erythropoietin (EPO), resulting in the overexpression of these genes (4).

Fructose-1,6-bisphosphatase (FBP1) is known as a rate-limiting enzyme in gluconeogenesis, which is an important process in cell energy metabolism. Recently, ubiquitous loss of FBP1 expression and its catalytic activity-independent function in ccRCC tissues has been identified, indicating that FBP1 may act as a repressor of HIF in the nucleus by binding to the HIF inhibitory domain (6). However, the association between FBP1 expression status and hypoxia-related gene expression has not been well investigated. Therefore, the present study aimed to explore whether the expression of hypoxia-related genes is correlated with FBP1 expression.

\section{Patients and methods}

Patients and samples. The study cohort consisted of 123 patients who underwent radical nephrectomy or partial nephrectomy for ccRCC between July and September 2012 at the Department of Urology, Peking University First Hospital (Beijing, China). General patient characteristics, including age, gender and tumor features, such as location, $\mathrm{T}$ stage and Fuhrman grade $(7,8)$, were collected. The present study was approved by the institutional review board of Peking University First Hospital. 

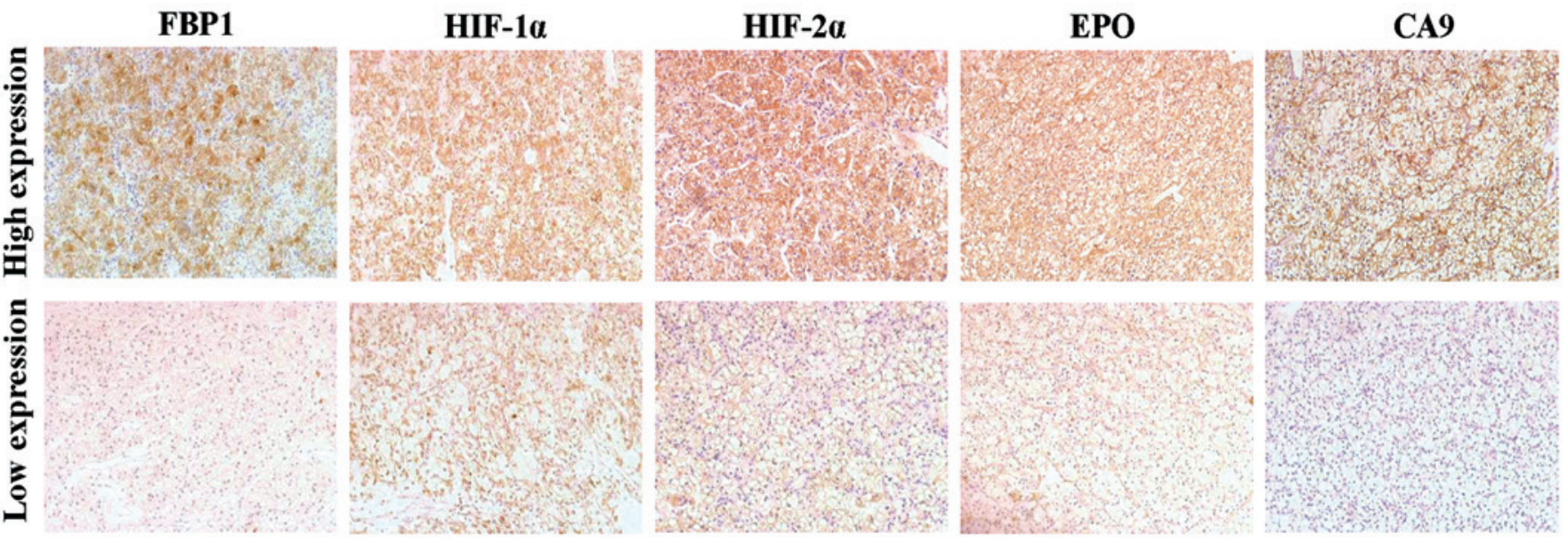

Figure 1. Representative immunohistochemical staining of clear cell renal cell carcinoma tissues with antibodies for FBP1, HIF-1 $\alpha$, HIF-2 $\alpha$, EPO and CA9 (DAB staining; magnification, x200). FBP1, fructose-1,6-bisphosphatase; HIF, hypoxia-induced factor; EPO, erythropoietin; CA9, carbonic anhydrase IX.

Samples and tissue microarray (TMA) construction. Following nephrectomy, tumor and adjacent control surgical specimens (at least $1 \mathrm{~cm}$ from the tumor tissues) were fixed in formaldehyde (Sinopharm Chemical Reagent Co., Ltd., Shanghai, China) and embedded in paraffin. Tissue sections $(4 \mu \mathrm{m})$ were stained with hematoxylin and eosin (OriGene Technologies, Inc., Beijing, China), and reviewed by two professional urological pathologists at the Department of Urology, Peking University First Hospital. The TMA base mold and Quick Ray tip (cat. no. UB06-3; Unitma Co., Ltd., Seoul, Korea) were used for TMA, according to the manufacturer's instruction.

Immunochemical staining and expression scoring of FBP1, HIF-1 $\alpha, H I F-2 \alpha, C A 9$ and EPO in the 123 ccRCC samples. Following deparaffinization with xylene and rehydration in graded ethanol (Sinopharm Chemical Reagent Co., Ltd.), the TMA slides $(4 \mu \mathrm{m})$ were heated in $10 \mathrm{mM}$ sodium citrate (pH 6.0; OriGene Technologies, Inc.) for antigen retrieval, incubated in $0.3 \% \mathrm{H}_{2} \mathrm{O}_{2}$ (OriGene Technologies, Inc.) for $30 \mathrm{~min}$ and blocked in $10 \%$ goat serum (OriGene Technologies, Inc.). The slides were then incubated with antibodies against FBP1 (rabbit monoclonal; 1:50 dilution; cat no. ab109020; Abcam, Cambridge, MA, USA), HIF-1 $\alpha$ (rabbit polyclonal; 1:50 dilution; cat no. sc-10790; Santa Cruz Biotechnology, Inc., Dallas, TX, USA), HIF-2 $\alpha$ (rabbit polyclonal; 1:40 dilution; cat no. ab199; Abcam), CA9 (rabbit polyclonal; 1:1,000 dilution; cat no. ab15086; Abcam) and EPO (rabbit polyclonal; 1:100 dilution; cat no. ab30545; Abcam) overnight at $4^{\circ} \mathrm{C}$. After washing with $0.01 \mathrm{M}$ phosphate-buffered saline and incubating with the appropriate secondary antibody (polyperoxidase-anti-rabbit immunoglobulin G; catalog no., PV-9001; OriGene Technologies, Inc.), the slide was developed by DAB staining (OriGene Technologies, Inc.). Immunohistochemical staining was evaluated by two independent pathologists using an Olympus CK40 microscope (Olympus Corporation, Tokyo, Japan). The staining intensity was represented by intensity score, was which was follows: 0 , no staining; 1, light yellow; 2 , brown-yellow; and 3, sepia. Tumor samples with an intensity score of 0 or 1 were classified as low expression and samples with an intensity score of 2 or 3 were classified as high expression (Fig. 1).
Statistical analysis. Data is presented as the mean \pm standard deviation and the median value. Immunohistochemical assessment was repeated three times for each sample. The correlation between FBP1 expression and clinicopathological factors or hypoxia-related protein expression were analyzed by $\chi^{2}$ and Fisher's exact tests. Differences in FBP1 expression between tumor tissues and adjacent normal tissues was calculated by using the Wilcoxon rank sum test. SPSS software version 19.0 (IBM SPSS, Armonk, NY, USA) was used to perform statistical analysis, and $\mathrm{P}<0.05$ indicated a statistically significant difference.

\section{Results}

Clinicopathological characteristics and FBPI expression status in ccRCC tumor tissues. Surgical ccRCC samples were obtained from 123 patients ( 83 males and 40 females). The mean age was $55.1 \pm 12.3$ years old, 62 patients $(50.4 \%)$ were aged $\leq 55$ years old and 61 patients $(49.6 \%)$ were aged $>55$ years old. Using the TNM staging system, tumors were classified as T1a in 59 cases $(48.0 \%)$, T1b in 39 cases $(31.7 \%)$, $\mathrm{T} 2$ in 8 cases $(6.5 \%)$ and $\mathrm{T} 3$ in 17 cases $(13.8 \%)$. According to the Fuhrman grading system, tumors were graded as G1 in 42 cases (34.1\%), G2 in 73 cases (59.4\%) and G3 in 8 cases $(6.5 \%)$ (Table I).

Immunohistochemistry staining revealed significantly higher rates of low FBP1 expression in tumor tissues compared with adjacent healthy tissues $(\mathrm{P}<0.001)$. The rate of low FBP1 expression in ccRCC tissues was $77.2 \%$ (95/123 cases) while the rate in adjacent normal tissues was $8.1 \%$ (10/123 cases; data not shown). In the ccRCC tumor tissues, 28 cases $(22.8 \%)$ were identified as exhibiting high FBP1 expression and 95 cases $(77.2 \%)$ exhibited low expression. No correlations were identified between FBP1 expression level status, and age, gender, $\mathrm{T}$ stage or Fuhrman grade in the ccRCC patients (Table I).

Correlation of FBPl expression with HIF-1 $\alpha, H I F-2 \alpha$, EPO and CA9 expression in ccRCC tumor tissues. HIF-1 $\alpha$, HIF-2 $\alpha$, EPO and CA9 were highly expressed in the majority of samples (HIF-1 $\alpha$ in 101/123 cases, $82.1 \%$; HIF-2 $\alpha$ in $77 / 123$ cases, $62.6 \%$; CA9 in 77/123 cases, $62.6 \%$; and EPO 
Table I. Correlation between FBP1 expression and clinicopathological factors in clear cell renal cell carcinoma tissues.

\begin{tabular}{|c|c|c|c|c|c|}
\hline \multirow[b]{2}{*}{ Variable } & \multirow[b]{2}{*}{ Patients $(n=123)$} & \multicolumn{2}{|c|}{ FBP1 expression } & \multirow[b]{2}{*}{$\chi^{2}$} & \multirow[b]{2}{*}{ P-value } \\
\hline & & Low $(n=95)$ & High $(n=28)$ & & \\
\hline Age (years), mean \pm SD & $55.1 \pm 12.3$ & $55.3 \pm 11.9$ & $54.0 \pm 13.4$ & 0.827 & 0.363 \\
\hline Gender, n (\%) & & & & 1.765 & 0.184 \\
\hline Male & $83(67.5)$ & $67(54.5)$ & $16(13.0)$ & & \\
\hline Female & $40(32.5)$ & $28(22.8)$ & $12(9.7)$ & & \\
\hline T stage, n (\%) & & & & 1.203 & 0.752 \\
\hline T1a & $59(48.0)$ & $48(39.0)$ & $11(8.9)$ & & \\
\hline $\mathrm{T} 1 \mathrm{~b}$ & $39(31.7)$ & $29(23.6)$ & $10(8.1)$ & & \\
\hline $\mathrm{T} 2$ & $8(6.5)$ & $6(4.9)$ & $2(1.6)$ & & \\
\hline $\mathrm{T} 3$ & $17(13.8)$ & $12(9.8)$ & $5(4.1)$ & & \\
\hline Fuhrman grade, n (\%) & & & & 2.025 & 0.363 \\
\hline G1 & $42(34.1)$ & $35(28.5)$ & $7(5.7)$ & & \\
\hline $\mathrm{G} 2$ & $73(59.4)$ & $55(44.7)$ & $18(14.6)$ & & \\
\hline G3 & $8(6.5)$ & $5(4.1)$ & $3(2.4)$ & & \\
\hline
\end{tabular}

FBP1, fructose-1,6-bisphosphatase; SD, standard deviation.

Table II. Correlation between expression of FBP1, and HIF1 $\alpha$, HIF2 $\alpha$, CA9 and EPO in clear cell renal cell carcinoma.

\begin{tabular}{|c|c|c|c|c|c|}
\hline \multirow[b]{2}{*}{ Expression } & \multirow[b]{2}{*}{ Patients, n (\%) } & \multicolumn{2}{|c|}{ FBP1 expression, n (\%) } & \multirow[b]{2}{*}{$\chi^{2}$} & \multirow[b]{2}{*}{ P-value } \\
\hline & & Low $(\mathrm{n}=95)$ & High $(n=28)$ & & \\
\hline HIF- $1 \alpha$ & & & & 7.897 & 0.005 \\
\hline Low & 22 (17.9) & $22(23.2)$ & $0(0.0)$ & & \\
\hline High & $101(82.1)$ & $73(76.8)$ & $28(100.0)$ & & \\
\hline HIF- $2 \alpha$ & & & & 2.380 & 0.123 \\
\hline Low & $46(37.4)$ & $39(41.1)$ & $7(25.0)$ & & \\
\hline High & $77(62.6)$ & $56(58.9)$ & $21(75.0)$ & & \\
\hline CA9 & & & & 0.428 & 0.513 \\
\hline Low & $46(37.4)$ & 37 (38.9) & $9(32.1)$ & & \\
\hline High & $77(62.6)$ & $58(61.1)$ & $19(67.9)$ & & \\
\hline EPO & & & & 6.640 & 0.010 \\
\hline Low & $57(46.3)$ & $50(52.6)$ & $7(25.0)$ & & \\
\hline High & $66(53.7)$ & $45(47.4)$ & $21(75.0)$ & & \\
\hline
\end{tabular}

FBP1, fructose-1,6-bisphosphatase; HIF, hypoxia-induced factor; CA9, carbonic anhydrase IX; EPO, erythropoietin.

in 66/123 cases, 53.7\%; Table II). The expression of HIF-1 $\alpha$ and EPO were significantly correlated with FBP1 $(\mathrm{P}=0.005$ and $\mathrm{P}=0.010$, respectively; Table II). However, this significant correlation was not observed between HIF $2 \alpha(\mathrm{P}=0.123)$ or CA9 $(\mathrm{P}=0.513)$ expression, and FBP1 expression.

\section{Discussion}

The present study analyzed the association between FBP1 expression and the expression of various hypoxia-related proteins in ccRCC samples. The majority of ccRCC samples exhibited low expression of FBP1, accompanied by high expression of HIF-1 $\alpha$ and EPO. However, there was not a significant association between low FBP1 expression, and HIF- $2 \alpha$ and CA9 expression.

Low expression of FBP1 has previously been observed in human hepatocellular carcinoma (HC), colon cancer (CC), breast cancer (BC), gastric cancer (GC) and ccRCC tissues (6,9-11). The current data is consistent with the latter study. The reason for low FBP1 expression in $\mathrm{HC}, \mathrm{CC}, \mathrm{BC}$ and $\mathrm{GC}$ has been identified as hypermethylation of the promoter region of the FBPl gene (9-11). However, the mechanism of FBP1 inhibition in ccRCC tissues has not been clearly identified and requires further investigation $(12,13)$. 
Recently, an association between FBPI expression and various pathological variables in patients with ccRCC was demonstrated at the transcription level (6). By contrast, the current results did not identify a significant association between FBP1 protein expression level and $\mathrm{T}$ stage $(\mathrm{P}=0.75)$ or Fuhrman grade $(\mathrm{P}=0.36)$ in ccRCC. This conflicting association between FBP1 mRNA and FBP1 protein level may be partially due to the high proportion of patients with low $\mathrm{T}$ stage $(\mathrm{T} 1+\mathrm{T} 2,86.2 \%)$ and low Fuhrman grade $(\mathrm{G} 1+\mathrm{G} 2$, $93.5 \%$ ) in the current cohort. Analysis of a greater number of ccRCC cases with various $\mathrm{T}$ stages and Fuhrman grades are required to understand the clinical significance of FBP1 expression levels in ccRCC.

$H I F-1 \alpha$ and $H I F-2 \alpha$ are the two most important hypoxia-related genes, and are regulated by VHL protein and oxygen in the local environment. HIF-1 $\alpha$ and HIF-2 $\alpha$ are overexpressed in various types of cancer, including melanoma and breast cancer (14-16), and have a role of tumorigenesis and tumor progression. However, these two subunits occasionally have different effects on cell biological behavior (17). HIF1 $\alpha$ dominantly regulates processing mechanisms, particularly the glucose processing mechanism, while HIF2 $\alpha$ influences various processes, including tumor cell growth (18). The present study observed that FBP1 low expression is associated with high expression of HIF1 $\alpha$ but not of HIF $2 \alpha$. In agreement with this finding, FBP1 is a critical enzyme in glucose metabolism, with certain research indicating that FBP1 may inhibit the function of HIF located in the nucleus (6); whether HIF1 $\alpha$ can regulate FBP1 expression has not been well discussed. Identifying the role of HIF1 $\alpha$ in the regulation of FBP1 expression may propose a novel function of HIF1 $\alpha$ and may be useful for clarifying ccRCC tumorigenesis.

EPO is widely used to treat tumor-related anemia, however, the effect of EPO on RCC has not been well delineated (19). Several studies observed that exogenous recombinant human EPO inhibits cancer progression, however, other studies indicated that it promotes cancer progression (20-22). EPO expression under a hypoxic environment is predominantly regulated by HIF $2 \alpha$ (23). In the present study, it was identified that FBP1 expression is significantly associated with EPO, but is not significantly associated with HIF2 $\alpha$. These findings indicate that FBP1 may directly interact with EPO expression. Understanding the interaction between FBP1 and EPO may aid in comprehending the role of FBP1 and EPO in ccRCC.

In conclusion, FBP1 expression was positively correlated with the expression levels of HIF-1 $\alpha$ and EPO in ccRCC tissues. The current findings confirm the association between FBP1 and hypoxia-related gene expression, and may facilitate understanding of the mechanisms of ccRCC tumorigenesis.

\section{Acknowledgements}

The present study was supported by grants from the Program for New Century Excellent Talents in Universities (grant no. NCET-10-0190) and the National Natural Science Foundation of China (grant nos. 81172418 and 81172419). The abstract was published as AB180 in Transl Androl Urol 4 (Suppl 1), 2015.

\section{References}

1. Siegel R, Naishadham D and Jemal A: Cancer statistics, 2013. CA Cancer J Clin 63: 11-30, 2013.

2. Kim WY and Kaelin WG: Role of VHL gene mutation in human cancer. J Clin Oncol 22: 4991-5004, 2004.

3. Latif F, Tory K, Gnarra J, Yao M, Duh FM, Orcutt ML, Stackhouse T, Kuzmin I, Modi W, Geil L, et al: Identification of the von Hippel-Lindau disease tumor suppressor gene. Science 260: 1317-1320, 1993.

4. Clark PE: The role of VHL in clear-cell renal cell carcinoma and its relation to targeted therapy. Kidney Int 76: 939-945, 2009.

5. Arjumand W and Sultana S: Role of VHL gene mutation in human renal cell carcinoma. Tumour Biol 33: 9-16, 2012.

6. Li B, Qiu B, Lee DS, Walton ZE, Ochocki JD, Mathew LK, Mancuso A, Gade TP, Keith B, Nissim I and Simon MC: Fructose-1,6-bisphosphatase opposes renal carcinoma progression. Nature 513: 251-255, 2014.

7. Elmore JM, Kadesky KT, Koeneman KS and Sagalowsky AI: Reassessment of the 1997 TNM classification system for renal cell carcinoma. Cancer 98: 2329-2334, 2003.

8. Hong SK, Jeong CW, Park JH, Kim HS, Kwak C, Choe G, Kim HH and Lee SE: Application of simplified Fuhrman grading system in clear-cell renal cell carcinoma. BJU Int 107: 409-415, 2011.

9. Chen M, Zhang J, Li N, Qian Z, Zhu M, Li Q, Zheng J, Wang X and Shi G: Promoter hypermethylation mediated downregulation of FBP1 in human hepatocellular carcinoma and colon cancer. PloS One 6: e25564, 2011.

10. Dong C, Yuan T, Wu Y, Wang Y, Fan TW, Miriyala S, Lin Y, Yao J, Shi J, Kang T, et al: Loss of FBP1 by Snail-mediated repression provides metabolic advantages in basal-like breast cancer. Cancer Cell 23: 316-331, 2013.

11. Liu X, Wang X, Zhang J, Lam EK, Shin VY, Cheng AS, Yu J, Chan FK, Sung JJ and Jin HC: Warburg effect revisited: An epigenetic link between glycolysis and gastric carcinogenesis. Oncogene 29: 442-450, 2010.

12. Alderton GK: Tumorigenesis: FBP1 is suppressed in kidney tumours. Nat Rev Cancer 14: 575, 2014.

13. Phillips R: Kidney cancer: FBP1 depletion feeds ccRCC. Nat Rev Urol 11: 482, 2014.

14. Giatromanolaki A, Sivridis E, Kouskoukis C, Gatter KC, Harris AL and Koukourakis MI: Hypoxia-inducible factors 1alpha and 2alpha are related to vascular endothelial growth factor expression and a poorer prognosis in nodular malignant melanomas of the skin. Melanoma Res 13: 493-501, 2003.

15. Theodoropoulos VE, Lazaris A, Sofras F, Gerzelis I, Tsoukala V, Ghikonti I, Manikas K and Kastriotis I: Hypoxia-inducible factor 1 alpha expression correlates with angiogenesis and unfavorable prognosis in bladder cancer. Eur Urol 46: 200-208, 2004.

16. Helczynska K, Larsson AM, Holmquist Mengelbier L, Bridges E, Fredlund E, Borgquist S, Landberg G, Påhlman S and Jirström K: Hypoxia-inducible factor-2alpha correlates to distant recurrence and poor outcome in invasive breast cancer. Cancer Res 68: 9212-9220, 2008.

17. Keith B, Johnson RS and Simon MC: HIF1 $\alpha$ and HIF2 $\alpha$ : Sibling rivalry in hypoxic tumour growth and progression. Nat Rev Cancer 12: 9-22, 2011.

18. Rankin EB and Giaccia AJ: The role of hypoxia-inducible factors in tumorigenesis. Cell Death Differ 15: 678-685, 2008.

19. Morais C, Johnson DW, Vesey DA and Gobe GC: Functional significance of erythropoietin in renal cell carcinoma. BMC Cancer 13: 14, 2013.

20. Abhold E, Rahimy E, Wang-Rodriguez J, Blair KJ, Yu MA, Brumund KT, Weisman RA and Ongkeko WM: Recombinant human erythropoietin promotes the acquisition of a malignant phenotype in head and neck squamous cell carcinoma cell lines in vitro. BMC Res Notes 4: 553, 2011.

21. Phillips TM, Kim K, Vlashi E, McBride WH and Pajonk F: Effects of recombinant erythropoietin on breast cancer-initiating cells. Neoplasia 9: 1122-1129, 2007.

22. Zhou B, Damrauer JS, Bailey ST, Hadzic T, Jeong Y, Clark K, Fan C, Murphy L, Lee CY, Troester MA, et al: Erythropoietin promotes breast tumorigenesis through tumor-initiating cell self-renewal. The Journal of clinical investigation 124: 553-563, 2014.

23. Rankin EB, Biju MP, Liu Q, Unger TL, Rha J, Johnson RS, Simon MC, Keith B and Haase VH: Hypoxia-inducible factor-2 (HIF-2) regulates hepatic erythropoietin in vivo. J Clin Invest 117: 1068-1077, 2007. 